\title{
Emptying the Nest
}

\author{
Kimberly Barrett and Jacqueline Bonneville
}

You would think that after spending most of our careers helping literally thousands of people send their daughters and sons off to college, we could avoid the emotional ordeal that is the "empty nest syndrome." Think again. In fact we are grappling with two phases of emptying the nest as we write this. Last fall one of us had a daughter who started kindergarten while the other sent her son off to college a few hours away. We believe that some of our insights might be helpful to colleagues as they go through this transition themselves or help others navigate these waters in their roles as orientation professionals.

As we shared the adventures of our children with each other over the past few months, we have been struck by how the first test flight into the K-12 system can provide a glimpse at what to expect as our children fly solo into the world of college and beyond. We identified three areas of concern that we appear to share with many parents as our children headed out on their own. They were: how to keep the lines of communication open, handling the endless and at times impenetrable educational bureaucracy, and trusting our children's ability to make good choices.

Looking back, our pre-schoolers had little need for formal communication with us. Early on, we like many parents, interacted so often with our children that it was like watching their little lives on a 24-hour reality show. However, as soon as they entered formal education outside the home we became acutely aware of the fact that at least for a few hours during the day, our children were pretty much inaccessible to us. That is why one of us picks her daughter up each day and can't seem to stop herself from asking question after question (Who did you play with at recess? What did you learn today? What did you eat today? and on and on). We become dependent on our children to tell us about their day, and this can be hard.

The need to help our young children, as Montessori educators put it, "use their words" effectively with us and others became critically important. However, be warned that if you are successful in this effort, there may be times when you get a little too much information, particularly during the junior high and high school years. Nonetheless, just tolerate it because once they stop returning home at the end of the day after setting out on their own for college and beyond, you will appreciate hearing the blow by blow, intimate details of their lives. As a college parent you may actually find yourself enjoying those phone calls home just

Kimberly Barrett (barrettka@montevallo.edu ) is the Vice President for Student Affairs at the University of Montevallo in Alabama, and Jacqueline Bonneville (bonnevjk@uwec.edu) is the Coordinator for New Student Orientation at the University of Wisconsin, Eau Claire. 
to stay current on their day to day happenings.

Our most important task as parents has been to become good listeners. For the majority of parents, this means learning to bite our tongues and give advice sparingly. When our desire to fix everything for these children (e.g., "No one sits with me on the bus" (preschool daughter), "Someone told me that my hair was puffy" (same daughter), "My neighbors are too loud" (college son)) who are so precious to us gets in the way, we must remember that one day we won't be there to tell them how it should be done. It's better to let them make a few mistakes before they leave the nest while the stakes are low. Through this process, children seem to get a sense of unconditional positive regard from us and come to understand that what they have to say is important.

Another challenge we face as parents sending our children off to new schools is dealing with educational bureaucracy. Again we found that our own experiences in a variety of educational institutions did not prevent us from feeling pretty clueless about how things are done within our son and daughter's new "homes away from home." As parents, we were faced with the same questions that we as professionals address during orientation about classes, grades, tests, food, and fees. We've come to the conclusion that the best way we can assist our children through this bureaucracy is to help them become assertive self advocates. Although what it means to advocate for yourself at 5 and 18 years of age is very different, parents can never start too soon in making sure that their students develop strategies to get the information and help they need for themselves.

Parents can help in this regard by being their children's back-up. If they come to a dead end in navigating the bureaucracy, be there with a suggestion about who they might contact next on-site to assist them with their questions and problems. This means that we must stay engaged and informed, not so that we can intervene with school officials, but so that we can be the power behind (emphasis on behind) our children as they take on the system. We will instill a sense of self efficacy in our children if they come to understand early that they can be agents of positive change in their own lives.

Ultimately, the question that nags at each of us as our children leave our protective reach is whether they will be able to make good choices - choices that have a good outcome for them as well as choices that are ethical. Whether it's getting on the correct bus, looking both ways as they cross the street, driving the speed limit, using credit cards responsibly, or treating others with respect - these are the issues that can keep us awake at night. They are especially troubling if we don't have faith in the job we've done as parents and in who our children have become. Now that we have given it some thought, it seems that the primary job we have as parents is preparing our children and ourselves for emptying the nest. To do this we must embrace a relationship that will evolve from dependence and obedience to independence and finally to a healthy interdependence based on trust and mutual respect.

Although it is a labor of love, it is also hard work. Parents can be bolstered by the fact that getting children to successfully "empty the nest" results in a silver lining. It may seem like a guilty pleasure at first, but you get used to it. For 
example, instead of standing in line for the latest video game, you may stand in line for the latest art exhibit. Or if you are at the "test flight" stage and the college phase seems far away, you may get a day off now and then while children are in school where your time is your own. An uninterrupted rendezvous with your partner over lunch or dinner - enough said about that - can be another benefit. Passing through or helping others navigate the academic transitions of life with children or family members may certainly bring challenges, but an intentional developmental approach to launching the next child or the next class of new students ensures that the launch ultimately will be successful and rewarding. 